This is the final peer-reviewed accepted manuscript of:

Barichella, M., Cereda, E., Cassani, E., Pinelli, G., lorio, L., Ferri, V., Privitera, G., Pasqua, M., Valentino, A., Monajemi, F., Caronni, S., Lignola, C., Pusani, C., Bolliri, C., Faierman, S.A., Lubisco, A., Frazzitta, G., Petroni, M.L., Pezzoli, G., 2017. Dietary habits and neurological features of Parkinson's disease patients: Implications for practice. Clin. Nutr. 36, 1054-1061. https://doi.org/10.1016/j.clnu.2016.06.020

The final published version is available online at:

https://doi.org/10.1016/j.clnu.2016.06.020

Rights / License:

The terms and conditions for the reuse of this version of the manuscript are specified in the publishing policy. For all terms of use and more information see the publisher's website.

This item was downloaded from IRIS Università di Bologna (https://cris.unibo.it/)

When citing, please refer to the published version. 


\title{
Dietary habits and neurological features of Parkinson's disease patients: Implications for practice
}

\author{
Michela Barichella ${ }^{a}$, Emanuele Cereda b, *, Erica Cassani ${ }^{a}$, Giovanna Pinelli ${ }^{a}$, \\ Laura Iorio ${ }^{a}$,Valentina Ferri ${ }^{a}$, Giulia Privitera ${ }^{a}$, Marianna Pasqua a , Angela \\ Valentino ${ }^{\text {a }}$, Fatemeh Monajemi ${ }^{\text {a }}$, Serena Caronni ${ }^{\text {, }}$ Caterina Lignola ${ }^{a}$, \\ Chiara Pusani ${ }^{a}$,Carlotta Bolliri a, Samanta A. Faierman ${ }^{a}$, Alessandro Lubisco \\ c, Giuseppe Frazzitta ${ }^{d}$, Maria L. Petroni e, Gianni Pezzoli a \\ a Parkinson Institute, ASST G.Pini-CTO, ex ICP, Milan, Italy \\ ${ }^{\mathrm{b}}$ Nutrition and Dietetics Service, Fondazione IRCCS Policlinico San Matteo, Pavia, Italy \\ 'Department of Statistical Sciences " $P$. Fortunati", University of Bologna, Bologna, Italy \\ ' Department of Parkinson Disease Rehabilitation, Moriggia-Pelascini Hospital, Gravedona ed Uniti, \\ Fondazione Europea Ricerca Biomedica (FERB), \\ "S.Isidoro" Hospital, Trescore Balneario, Italy \\ e Department of Functional Rehabilitation, "Sol et Salus" Hospital, Torre Pedrera, Rimini, Italy
}

* Corresponding author. Fondazione IRCCS Policlinico San Matteo, Viale Golgi 19, 27100 Pavia, Italy. Tel.: p39 0382 501615; fax: p39 0382502801.

E-mail address: e.cereda@smatteo.pv.it (E. Cereda).

\section{Summary}

Background \& aims: Parkinson's disease (PD) patients can benefit considerably from appropriate nutritional care, particularly from diet. However, there is limited evidence on the eating habits of PD patients and their relationship with the features of the disease.

Methods: We conducted a large case-control study. Consecutive PD patients ( $1 / 4600$ ) receiving systematic nutritional care and healthy controls ( $\mathrm{N} 1 / 4600)$ matched (1:1) for age, gender, education, physical activity level and residence were studied using a 66-item food frequency questionnaire. The relationship between dietary habits and the following features of PD were investigated in patients: body weight, energy balance, constipation, and levodopa therapy (dose) and its related motor complications.

Results: PD patients had lower BMI and reported higher food intake than controls. BMI was found to be inversely associated with disease duration and severity, and levodopa-related motor complications, whereas energy intake was positively associated with these variables. An increase in protein intake by $10 \mathrm{~g}$ over physiological requirements $(0.8 \mathrm{~g} / \mathrm{kg} /$ day $)$ corresponded to a mean increase in levodopa dose of $0.7 \mathrm{mg} / \mathrm{kg} / \mathrm{day}$. Constipation was also associated with higher levodopa requirements. Finally, protein intake and its distribution throughout the day influenced levodoparelated motor complications. Conclusion: The management of protein intake and the treatment of constipation should be considered to be an integral part of the care of PD patients. Attention should always be focused on energy intake also. This would result in the maintenance of nutritional status, the optimization of levodopa-therapy and the minimization of its related motor complications. 


\section{Introduction}

Nutritional assessment and dietary therapy have an important role to play in the integrated management of PD [1]. First of all, calorie intake should be verified. Indeed, body weight changes have been recorded throughout the course of the disease and are related to its duration. Weight loss can occur before the clinical diagnosis of the disease, before onset of symptoms [2]. Then, during the first years after onset of symptoms, body weight usually increases, probably on account of a reduction in motor function and/or the voracity that is sometimes induced by treatment with levodopa and dopamine agonists $[1,3]$. On the contrary, during the advanced stages of the disease, progressive body weight loss occurs, probably on account of the increase in energy expenditure produced mainly by muscle hypertonia and any dyskinesias [1,3-5]. In some patients calorie-rich food supplements may be required to counteract body weight loss, meeting calorie requirements [6]. An indirect demonstration that dyskinesias have an important role to play in energy consumption is the body weight gain that occurs in patients who undergo deep brain stimulation (DBS), which reduces motor fluctuations [7]. However, the specific mechanisms underlying changes in body weight after DBS have yet to be determined, as an association between weight gain and the reduction in motor symptoms has not always been reported $[8,9]$ and the reduction in dyskinesias may be just one of the factors involved.

Regarding the intake of macronutrients, amino acids (especiallythe neutral ones) introduced with food compete with levodopa for intestinal absorption and transport through the blood brain barrier, reducing its bioavailability $[1,10,11]$. To optimize the effect of levodopa, especially as the diseases progress and motor fluctuations appear, PD patients should be advised to follow a protein redistribution diet i.e. protein restriction at breakfast and at lunch followed by unrestricted protein consumption at dinner, which is to include a second main course with meat, poultry or fish [1,10-12]. The objective of this redistribution is to meet daily protein requirements, which should be $0.8-1.0$ $\mathrm{g} / \mathrm{kg}$ of body weight $[10,13]$. In some patients the consumption of special foods devoid of protein at lunch may be required to reduce the amount of protein introduced and competition with pharmacological therapy $[4,14,15]$. Regarding micronutrients, PD patients have been found to lack vitamin $\mathrm{D}$ (low concentrations in plasma). The deficiency of this vitamin appears to be greater in PD patients than in the healthy population [16].

Moreover, dietary therapy is a strategy designed to counteract non motor symptoms of nutritional interest [1]. About $60 \%$ of PD patients suffer from constipation, making a high fiber diet associated with correct hydration essential [1,17-19]. For all these rea- sons, the diet of PD patients should be monitored. Studies on the dietary habits of PD patients may provide data of considerable interest. To date such studies have been performed only on small samples of patients $[20,21]$. The objective of our work was to describe the dietary habits of a large sample of Italian PD patients in a casecontrol study, using a freeware investigational software and assessing the association with the neurological features of the patient. In particular, attention was focused on the following issues: body weight and energy balance throughout the course of the disease, constipation and the relationship among protein intake, levodopa therapy and its related motor complications.

\section{Materials and methods}


Study population (patients and controls)

We conducted a large, observational case-control study (January-September 2015). Dietary habits and lifestyle of patients suffering from idiopathic Parkinson's disease (PD) [22] and with normal cognitive functions (MMSE > 24 points) were the subject of this study. PD patients consecutively attending the out-patient clinic of the Parkinson Institute (ASST G. Pini-CTO, ex ICP, Milan, Italy) and coming from all Regions of Italy were considered eligible for inclusion. The Parkinson Institute is located in Lombardy, the most populated Region of Italy (total inhabitants: 10003 419, www.demo.istat.it [accessed 18th January 2016]). At this Institute nutritional care is provided routinely and all patients receive specific dietary advice for the management of any issue that may benefit from it. The anthropometric parameters and dietary habits of the patients were then compared with those of a control group matched (1:1) by gender, age ( \pm 1 year), physical activity level (major intensity levels e please see below) and geographical area (province of residence). Controls had to be cognitively intact and were selected among all the people in the electronic database of the "ON-GP" free online software, developed by the Grana Padano Observatory (OGP) $[23,24]$. Controls were selected among the spouses of the patients included or people accompanying them (community healthy controls) and patients attending the same hospital for other minor health reasons (hospital controls with minor neurologic, orthopedic, dermatologic or ophthalmologic disorders). Subjects and patients reporting the use of any type of dietary supplement and/or receiving artificial nutritional support were excluded. All the subjects recruited provided their informed consent to the study. The study was approved by the local Ethics Committee.

\section{Assessments}

On the same day, PD patients and controls underwent the following assessments:

1. Anthropometry e Anthropometric data were collected by well- trained dieticians in agreement with WHO indications [25]. Particularly, body weight and height were measured using the same portable calibrated flat scale provided with a telescopic vertical steel stadiometer (Wunder, Italy), while waist circumference was measured through plastic flexible tapes at the narrowest point between the lowest rib and the iliac crest.

2. Dietary habits e Dietary habits were investigated with a semi- quantitative 66-item Food Frequency Questionnaire (FFQ) $[23,24]$, with the objective of assessing the frequency of consumption of the main food groups and drinks over the last 12 months. Trained dieticians completed the questionnaire by interviewing patients directly (with the aid of caregivers whenever necessary to avoid missing items). 24-hour dietary recall associated with the use of a food atlas was also considered for consistency of portion size and to confirm adherence to a protein redistribution diet (PRD). PRD was defined as protein restriction (no high-protein food sources) at breakfast and at lunch followed by unrestricted protein consumption at dinner (second main course with meat, poultry or fish) [10] for 5 days or more per week. The online "ON-GP" Software freeware was used for the assessment $[23,24]$ and daily calorie, macronutrient, micronutrient and fluid intakes were calculated using the Italian Food Composition Tables [26]. In this way any excesses and/or deficiencies were highlighted. Based on the data processed, the software enabled us to print a report containing personalized advice to give the patient. This software is also able to collect the following information: gender; age; geographical area (residence), level of education and type of occupation; anthropometric data (body weight, height, BMI, and waist circumference); time 
dedicated to household chores, free time dedicated to sedentary hobbies and physical activity. Based on information related to hours of sleep, as well as to the duration and the types of occupation and recreational activities, which are linked to specific (tabulated) energy costs per minute [27], it was possible to calculate the total energy cost of each task. The sum of these energy costs and resting energy expenditure (REE) e according to the HarriseBenedict equations [28] e enabled the calculation of total daily energy expenditure (TDEE). The mean of seven days was considered in the analysis. Therefore, the physical activity level (PAL) was expressed as the ratio of TDEE and REE and was grouped into major intensity levels ac- cording to age and gender (Supplementary Table 1).

Bowel habits e Presence of constipation was diagnosed according to Rome-III criteria [29]. PD features e Furthermore, the following clinical information was collected for all PD patients: duration of disease, Unified Parkinson Disease Rating Scale (UPDRS) from part I to part IV [30], disease severity (Hoehn and Yahr [HY] staging system) [31] and the daily dose of pharmacological therapy with levodopa ( $\mathrm{mg} /$ day and $\mathrm{mg} / \mathrm{kg} /$ day). In addition, the single items of UPDRS part IV were used to calculate subscores indicative of complications of therapy: dyskinesias (sum of items 32-to-35) and fluctuations, namely OFF periods (loss of efficacy of dopaminergic therapy resulting in the exacerbation of motor symp-toms; sum of items 36-to-39) [30,32].

\section{Statistical analysis}

All analyses were performed using the SPSS 23.0 for Windows (SPSS Inc., Chicago, Illinois). All statistical tests were two-tailed, and a P-value $<0.05$ was assumed to be statistically significant. Between-group comparisons related to continuous variables were performed using the Student's ttest (between two groups) and ANOVA (among multiple groups). Particularly, a paired t-test was used for comparisons between patients and matched controls, while in the other cases an unpaired t-test was adopted. Categorical variables were analyzed by Fisher's exact test. First, demographic and nutritional features, and dietary habits were compared be- tween PD patients and controls. Then, the characteristics of patients were compared across tertiles of disease duration, and by constipation, and adherence to protein redistribution diet. The strength of associations among nutritional status, disease duration, energy balance (difference between energy intake and TDEE) and motor complications (UPDRS dyskinesias and OFF-state scores) in patients receiving levodopa therapy were investigated using partial correlation models adjusted for sex, age and the use of dopamine agonists. Finally, linear regression analysis was conducted to quantify the association of independent non collinear variables with daily levodopa dose. No specific sample size calculation was conducted for the present study.

\section{Results}

A total of 600 PD patients (males, 53.8\%) and 600 controls (taken from community, 69\%) were interviewed. Demographic, clinical, anthropometric and nutritional features of the study population (patients and controls) are reported in Table 1. PD patients weighed less and had lower BMI than controls (Fig. 1), although their abdominal fat was similar. However, despite lower REE and TDEE, the calorie intake of PD patients was higher. Except for alcohol consumption, the total calorie, macronutrient and micronutrient intakes of PD patients were higher than the corresponding intakes of controls. In particular, mean daily protein intake was $1.0 \mathrm{~g} / \mathrm{kg}$ in controls vs $1.2 \mathrm{~g} / \mathrm{kg}$ in PD patients $(P<0.001)$. Moreover, lower coffee and tea consumption in PD patients was confirmed $(55 \pm 47 \mathrm{vs}$. 
$70 \pm 50 \mathrm{~g} /$ day [P < 0.001]; tea, $87 \pm 141$ vs. $108 \pm 130 \mathrm{~g} /$ day [P 0.009]). We also observed that patients who were taking dopamine agonists had a higher calorie intake (34.4 \pm 11.1 vs.

$32.1 \pm 10.3 \mathrm{kcal} / \mathrm{kg} /$ day; P 0.009) notwithstanding similar BMI $(26.1 \pm 4.8$ vs. $25.9 \pm 4.9 \mathrm{~kg} / \mathrm{m} 2 ; \mathrm{P}$ $0.614)$. PD patients reported constipation more frequently than controls $(46.8 \%$ vs. $6.8 \% ; P<0.001)$. Although the analysis of dietary habits disclosed higher fiber intake in PD patients than controls, water intake was considerably lower. However, no significant differences were found between constipated and non-constipated patients in terms of macronutrient, micronutrient, fiber and water intakes (Supplementary Table 2). The latter were more frequently female, younger and had shorter duration of disease, less severe symptoms, were taking lower doses of levodopa and had higher BMI.

We also investigated potential associations between nutritional variables and duration of disease. As duration became longer we observed, besides progression of disease, progressive reduction in body weight, $\mathrm{BMI}$ and increase in protein and calorie intake, as well as reduction in REE, physical activity level and TDEE (Table 2). Consequently, the energy balance appears to be positive in PD patients (Fig. 2). Therefore, comparing the various disease duration strata with controls (data not shown), we observed once more greater calorie intake, whereas the micronutrient intake was significantly higher only in patients with duration of disease 6 years. Furthermore, none of the micronutrient levels were lower in controls than in patients with a shorter duration of disease ( $<6$ years).

Therefore, considering the interaction between dietary protein and levodopa therapy and its related motor complications, we carried out a sub-analysis on patients on levodopa therapy ( $N$ 510; $85 \%$ of the total PD cases). Besides confirming the inverse association between duration of disease and $\mathrm{BMI}$, as well as the direct association between duration of disease and energy balance and levodopa-related motor complications, the analysis (models adjusted for gender, age and the use of dopamine agonists) dis- closed: 1 ) an inverse correlation between BMI and both energy balance and motor complications; 2 ) a direct relationship between energy balance and motor complications (Supplementary Table 3). No associations between protein intake and levodopa-related motor complications (OFF and dyskinesias duration) were found (data not shown). Adherence to a PRD was recorded in 277 patients (54\%). The clinical and nutritional features of PD patients receiving levodopa by adherence to a PRD are presented in Supplementary Table 4.

Patients on a PRD were characterized by higher BMI despite lower protein and calorie intake. However, adherence to PRD did not result in significant differences in terms of the content in the other nutrients, with the exception of a lower intake of calcium, zinc and vitamin B12. Interestingly, PRD was associated with lower total daily levodopa dose and better OFF score. No difference was found in dyskinesia score. The inverse association between PRD and motor fluctuations (OFF score) was confirmed also by multivariate regression analysis including age at onset, gender, disease duration and levodopa dose $(\mathrm{mg} / \mathrm{kg})$ as covariates: $\beta$-coefficient, $0.4(95 \% \mathrm{Cl}, 0.6,0.0), \mathrm{P} 0.046$. Finally, variables associated with levodopa requirements $(\mathrm{mg} / \mathrm{kg} /$ day) were investigated. In sexadjusted multivariable linear regression analysis (Table 3 ) an independent positive correlation with age at onset, disease duration, HoehneYahr stage, constipation and protein intake $(\mathrm{g} / \mathrm{kg} /$ day) was recorded. In particular, an increase in protein intake by $10 \mathrm{~g}$ over physiological requirements $(0.8$ $\mathrm{g} / \mathrm{kg} /$ day) corresponded to a mean increase in levodopa dose of $0.7 \mathrm{mg} / \mathrm{kg} / \mathrm{day}$ (70 $\mathrm{kg}$ of body weight / 50 mg of levodopa per day). However, adherence to a PRD was independently associated with lower levodopa requirements.

\section{Discussion}


As far as we are aware, this is the first large-scale survey investigating the dietary habits of PD patients and their association with neurological features. In the present study, we have clearly highlighted the importance of routine nutritional care in PD. Compared to matched controls, PD patients had lower BMI and reported higher food intakes. Nutritional status and energy balance were found to be related to disease duration and severity, and also to levodopa-related motor complications. Despite the higher prevalence of constipation, dietary habits for the management of this non-motor symptom were likely sub-optimal. Nonetheless, constipation was associated with higher levodopa dosages, independently of disease duration. Finally, protein intake appeared to influence levodopa therapy and related motor fluctuations and complications.

\section{Body weight and energy balance}

In agreement with available literature, BMI was inversely associated with disease severity and was lower in PD patients than in matched healthy subjects [1,3,33-35]. However, the inverse association with disease duration still remains controversial. Previous studies on this topic have suggested that weight loss during the course of the disease may be secondary to the increase in energy expenditure associated with the worsening of motor symptoms e mainly rigidity e but also of levodopa-related motor complications, namely dyskinesias $[1,4,33]$. This hypothesis is supported by the interrelationships we observed between $\mathrm{BMI}$, energy balance, and the severity of motor fluctuations and complications. Interestingly, the association was independent of the use of dopamine-agonists, which are known to affect eating behavior $[2,35]$. However, the reduction in body weight appeared to occur despite the significant increase in calorie intake. It is reasonable to assume that the increase in calorie intake is secondary to, but is not enough to compensate for the increase in energy requirements associated with rigidity and dyskinesias. The role of disease-related modifications in energy requirements is also consistent with the decrease in metabolic rate and the increase in body weight that occur in patients who have undergone neurosurgical procedures for motor complications $[2,35,36]$. Besides, in some cases, after having had drug therapy and diet optimized, the use of oral nutritional hypercaloric supplements should be considered to manage body weight loss and risk of malnutrition due to severe dyskinesias. However, the role of other interacting factors potentially influ- encing energy balance cannot be excluded and still needs to be elucidated. Although PD patients are characterized by gut dysbiosis $[37,38]$ the presence of malabsorption is unlikely. On the other hand, a recent study has proposed the existence of different pat- terns of weight regulation and food intake, which are likely determined by different degrees of olfactory dysfunction [35,39].

Accordingly, severe olfactory dysfunction would result in a reduction in food intake and body weight, while mild dysfunction would be more likely be associated with their increase.

\subsection{Nutrient intakes}

Closely linked to food intake, which was higher in PD patients than in controls independently of disease duration, higher intake of several micronutrients was also observed in the whole patient population. Interestingly, the intakes of micronutrients in the first 5 years of the disease were comparable to those of matched controls. This may appear to be in contrast with previous findings, 
since some studies have reported a higher risk of developing PD in subjects with lower intakes of poly-unsaturated fatty acids, vitamin A, vitamin B12, vitamin E, folic acid and vitamin D [40].

However, it should be recognized that the association between single nutrients and the risk of PD is still controversial and needs to be clarified. The evidence from prospective investigations is limited and case- control studies e like the present survey e are less appropriate for the evaluation of a cause-effect relationship. Nonetheless, our study confirmed lower consumption of coffee and tea in PD patients. Finally, we observed that the intake of most nutrients appeared to be appropriate in both patients and controls. The exception was represented by vitamin D. Although the circulating levels of this vitamin depend on several factors e unexplored herein e we observed that mean intake was significantly lower than recommended dietary allowances (15 mg/day) [27] in both patients and controls. This condition may have important health implications and supplementation should be taken into consideration also because, specifically for PD, literature suggests that vitamin $\mathrm{D}$ may have neuroprotective effects on dopaminergic neurons [41].

\section{Protein intake and levodopa therapy}

Since it has been established that neutral amino acids and levodopa compete for transportation in the small intestine and at the blood-brain barrier, significant benefits could be achieved through adherence to PRD. These include the reduction in motor fluctuations and the improvement in quality of life associated with the efficacy of dopaminergic therapy [10,11]. Specific advice on this issue is systematically provided at our Institute and current results confirm that PRD offers improvement in motor fluctuations without inducing severe dyskinesias, provided that levodopa treatment regimens are optimized $[4,10,11,14,15]$. In line with this, we have also shown that adherence to PRD may have an economic impact in the long term, as it is associated with lower levodopa requirements. A highlight of this study is the correlation between excessive protein intake and levodopa therapy. This is an interesting finding as disease duration was directly associated with both levodopa dosage and protein intake. For this reason, in clinical practice, we could suggest both PRD diet and protein intake of $0.8 \mathrm{~g} / \mathrm{kg}$ of body weight to optimize levodopa dosage. An important outcome of our survey is also the safety of PRD when this dietary regimen is associated with routine nutritional care. In the past, PRD has raised concerns in terms of risk of inducing weight loss and nutritional deficiencies $[10,11]$. Indeed, it is associated with a lower intake of protein and other micronutrients whose primary sources are high-protein foods of animal origin (zinc, calcium and vitamin B12). On the other hand, all nutrient intakes (macro- and micro- nutrients) were likely to satisfy daily requirements. However, monitoring should be considered.

\section{Constipation}

Constipation is a highly prevalent condition in PD. In addition to avoiding a sedentary lifestyle, dietary modifications still are the first-line strategy to address this non-motor symptom $[1,18]$. Accordingly, patients should be advised to increase their fiber and water intakes, as these may positively affect bowel function by increasing fecal bulk and improving stool consistency. Overall, PD patients reported higher fiber intake, but also lower water intake than controls, while no difference was found between patients with and without constipation. It should be highlighted that in the presence of low water intake a high-fiber diet negatively affects stool consistency and bowel habits. Finally, we observed that constipation was associated with higher levodopa requirements. Increased 
transit time and gut dysbiosis may reasonably be considered to be responsible for higher degradation and reduced availability of levodopa therapy. This is consistent with previous observations that antibiotic therapy improves motor fluctuations [42]. Therefore, it is reasonable to take optimization of dietary habits into consideration to improve bowel habits.

\section{Limitations and strengths}

The main limitation of the present study is the cross-sectional design. Longitudinal studies are required to confirm the positive impact of diet on the major nutritional issues characterizing PD patients: body weight, constipation and diet-levodopa therapy interactions. Second, the present survey has been conducted at a single movement disorders clinic, in which nutritional care is integrated with neurologic clinical activities and is provided on a routine basis. Third, we have studied only patients with a MMSE score $>24$. Considering the prevalence of dementia in PD [43] the potential role of cognitive decline on dietary habits in PD deserves further investigation. Besides, assessment bias associated with the method used in the ascertainment of dietary habits should be acknowledged. Particularly, the rather limited number of food items (N 66) studied (compared to the range included in other available tools), the impact of seasonal variation on dietary reporting [44] and the risk of under- and over-reporting should be taken into account, although the administration method (direct interviewing and involvement of the caregiver) have partly over- come the last limitation listed. Also the method used for the assessment of PAL has limits, as the energy expenditure for the same physical activities may differ according to body weight. However, patients and controls were mostly sedentary and the relationship between energy expenditure and body weight is likely more complex in PD, since patients are characterized by higher lean body mass $[45,46]$. Finally, a higher number of controls (2:1 or 3:1), exclusively sampled from the community, would have further increased the power of our analysis and the strength of present findings. Nonetheless, this study enabled the identification of critical issues in the dietary management of this patient population. These factors clearly are the ones requiring the most attention to achieve further nutritional optimization.

\section{Conclusions and implications for practice}

Nutritional care should be considered to be an integral part of the care of PD patients. Attention should be always focused on calorie intake to avoid unintentional weight loss and on protein intake to avoid interactions with levodopa. This would result not only in adequate nutrient intake, but also in optimization of levodopa-therapy and related motor complications occurring during the course of the disease. Clinicians should also focus on the management of constipation, bearing in mind the potential impact on the management of dopaminergic therapy.

\section{Conflict of interest}

The authors have no conflicts of interest to declare.

\section{Acknowledgments}


Source of support: This work was supported by "Fondazione Grigioni per il Morbo di Parkinson" and "Brain and Malnutrition in Chronic Disease Association Onlus".

Study guarantor: Dr Cereda had full access to all of the data in the study and takes responsibility for the integrity of the data and the accuracy of the data analysis.

Statement of authorship: All the authors have participated sufficiently in the work to fulfil the criteria for authorship. Partic- ularly, the contributions were as follows:

Study concept and design: Barichella, Petroni, Pezzoli.

Acquisition of data: Pinelli, lorio, Ferri, Privitera, Pasqua, Valentino, Monajemi, Caronni, Lignola, Pusani, Bolliri, Faierman.

Analysis and interpretation of data: Barichella, Cereda, Cassani, Lubisco, Petroni, Pezzoli.

Drafting of the manuscript: Cereda, Cassani.

Critical revision of the manuscript for important intellectual content: Barichella, Cereda, Cassani, Lubisco, Petroni, Pezzoli.

Statistical analysis: Cereda, Lubisco.

Obtained funding: Barichella, Pezzoli.

Administrative, technical, or material support: Barichella, Petroni, Pezzoli.

Study supervision: Barichella, Pezzoli.

Full financial disclosures of all authors for the past 2 years: The authors also certify that over the last three years there were no affiliations with or involvement in any organization or entity with a direct financial interest in the subject matter or materials discussed herein. Emanuele Cereda has received consultancy honoraria and investigator grants from Nutricia Italia, Akern s.r.I., Wunder s.r.I. and the "Fondazione Grigioni per il Morbo di Parkinson".

The authors wish to thank Dr. Pier Danio Forni (OSC Healthcare S.r.I Unipersonale) and Consorizio Grana Padano for software use and management and Dr. Jennifer S Hartwig for assistance in editing the manuscript.

\section{References}

[1] Barichella M, Cereda E, Pezzoli G. Major nutritional issues in the management of Parkinson's disease. Mov Disord 2009 Oct 15;24(13):1881e92.

[2] Chen H, Zhang SM, Herna'n MA, Willett WC, Ascherio A. Weight loss in Parkinson's disease. Ann Neurol 2003 May;53(5):676e9.

[3] Barichella M, Marczewska A, Vairo A, Canesi M, Pezzoli G. Is underweightness still a major problem in Parkinson's disease patients? Eur J Clin Nutr 2003 Apr;57(4):543e7.

[4] Cereda E, Pezzoli G, Barichella M. Role of an electronic armband in motor function monitoring in patients with Parkinson's disease. Nutrition 2010 Feb;26(2):240e2. 
[5] Barichella M, Villa MC, Massarotto A, Cordara SE, Marczewska A, Vairo A, et al. Mini Nutritional Assessment in patients with Parkinson's disease: correlation between worsening of the malnutrition and increasing number of disease- years. Nutr Neurosci 2008 Jun;11(3):128e34.

[6] Barichella M, Madio C, Cassani E, Magris C, Pezzoli G. Oral high-calorie, low- protein supplements in a Parkinson's disease patient: a case report. Mov Disord 2011 Feb 1;26(2):354e5.

[7] Barichella M, Marczewska AM, Mariani C, Landi A, Vairo A, Pezzoli G. Body weight gain rate in patients with Parkinson's disease and deep brain stimu- lation. Mov Disord 2003 Nov;18(11):1337e40.

[8] Novakova L, Ruzicka E, Jech R, Serranova T, Dusek P, Urgosik D. Increase in body weight is a non-motor side effect of deep brain stimulation of the subthalamic nucleus in Parkinson's disease. Neuro Endocrinol Lett 2007 Feb;28(1):21e5.

[9] Ruzicka E, Novakova' L, Jech R, Urgosík D, Ruzicka F, Haluzík M. Decrease in blood cortisol corresponds to weight gain following deep brain stimulation of the subthalamic nucleus in Parkinson's disease. Stereotact Funct Neurosurg 2012;90(6):410e1.

[10] Cereda E, Barichella M, Pedrolli C, Pezzoli G. Low-protein and protein- redistribution diets for Parkinson's disease patients with motor fluctuations: a systematic review. Mov Disord 2010 Oct 15;25(13):2021e34.

[11] Cereda E, Barichella M, Pezzoli G. Controlled-protein dietary regimens for Parkinson's disease. Nutr Neurosci 2010 Feb;13(1):29e32.

[12] Olanow CW, Watts RL, Koller WC. An algorithm (decision tree) for the man- agement of Parkinson's disease (2001): treatment guidelines. Neurology 2001;56(11 Suppl. 5):S1e88.

[13] Bauer J, Biolo G, Cederholm T, Cesari M, Cruz-Jentoft AJ, Morley JE, et al. Ev- idence-based recommendations for optimal dietary protein intake in older people: a position paper from the PROT-AGE Study Group. J Am Med Dir Assoc 2013 Aug;14(8):542e59.

[14] Barichella M, Marczewska A, De Notaris R, Vairo A, Baldo C, Mauri A, et al. Special lowprotein foods ameliorate postprandial off in patients with advanced Parkinson's disease. Mov Disord 2006 Oct;21(10):1682e7.

[15] Barichella M, Savardi C, Mauri A, Marczewska A, Vairo A, Baldo C, et al. Diet with LPP for renal patients increases daily energy expenditure and improves motor function in parkinsonian patients with motor fluctuations. Nutr Neu- rosci 2007 JuneAug;10(3e4):129e35.

[16] Evatt ML, Delong MR, Khazai N, Rosen A, Triche S, Tangpricha V. Prevalence of vitamin D insufficiency in patients with Parkinson disease and Alzheimer disease. Arch Neurol 2008 Oct;65(10):1348e52.

[17] Barichella M, Cereda E, Madio C, lorio L, Pusani C, Cancello R, et al. Nutritional risk and gastrointestinal dysautonomia symptoms in Parkinson's disease outpatients hospitalised on a scheduled basis. Br J Nutr 2013 Jul 28;110(2): 347e53.

[18] Rossi M, Merello M, Perez-Lloret S. Management of constipation in Parkin- son's disease. Expert Opin Pharmacother 2015 Mar;16(4):547e57.

[19] Evatt ML, Chaudhuri KR, Chou KL, Cubo E, Hinson V, Kompoliti K, et al. Dys- autonomia rating scales in Parkinson's disease: sialorrhea, dysphagia, and constipation e critique and 
recommendations by movement disorders task force on rating scales for Parkinson's disease. Mov Disord 2009 Apr 15;24(5): 635e46.

[20] Lorefat B, Ganowiak W, Wissing U, Granerus AK, Unosson M. Food habits and intake of nutrients in elderly patients with Parkinson's disease. Gerontology 2006;52(3):160e8.

[21] Marczewska A, De Notaris R, Sieri S, Barichella M, Fusconi E, Pezzoli G. Protein intake in Parkinsonian patients using the EPIC food frequency questionnaire. Mov Disord 2006 Aug;21(8):1229e31.

[22] Hughes AJ, Ben-Shlomo Y, Daniel SE, Lees AJ. What features improves the accuracy of clinical diagnosis in Parkinson's disease: a clinicopathologic study. Neurology 2001;57:S34e8.

[23] Festi D, Colecchia A, Pini S, Scaioli E, Maffeis C, Coccheri S, et al. Development and application of a simple and powerful tool for nutrition and lifestyle ed-ucation for the Italian general population by general practitioners and family paediatricians. Mediterr J Nutr Metab 2009;2:139e44.

[24] Bollati V, Favero C, Albetti B, Tarantini L, Moroni A, Byun HM, et al. Nutrients intake is associated with DNA methylation of candidate inflammatory genes in a population of obese subjects. Nutrients 2014;6(10):4625e39.

[25] World Health Organization. Physical status: the use and interpretation of anthropometry. Report of a WHO Expert Committee. World Health Organ Tech Rep Ser 1995;854:1e452.

[26] Istituto Nazionale di Ricerca per gli Alimenti e la Nutrizione (I.N.R.A.N.). Tabelle di composizione degli Alimenti. Aggiornamento 2000. EDRA Medical Publishing and New Media; 2000.

[27] LARN: Livelli di Assunzione di Riferimento di Nutrienti ed energia per la popolazione italiana. IV Revisione, 2014.

[28] Frankenfield DC, Muth ER, Rowe WA. The Harris-Benedict studies of human basal metabolism: history and limitation. J Am Diet Assoc 1998;98:439e45.

[29] Drossman DA. The functional gastrointestinal disorders and the Rome III process. Gastroenterology 2006 Apr;130(5):1377e90.

[30] Fahn S, Elton RL, UPDRS Program Members. Unified Parkinson's disease rating scale. In: Fahn S, Marsden CD, Goldstein M, Calne DB, editors. Recent de- velopments in Parkinson's disease, vol. 2. Florham Park, NJ: Macmillan Healthcare Information; 1987. p. 153e63. 293e304.

[31] Hoehn M, Yahr M. Parkinsonism: onset, progression and mortality. Neurology 1967;17:427e42.

[32] Cilia R, Cereda E, Klersy C, Canesi M, Zecchinelli AL, Mariani CB, et al. Par- kinson's disease beyond 20 years. J Neurol Neurosurg Psychiatry 2015 Aug;86(8):849e55.

[33] Capecci M, Petrelli M, Emanuelli B, Millevolte M, Nicolai A, Provinciali L, et al. Rest energy expenditure in Parkinson's disease: role of disease progression and dopaminergic therapy. Park Relat Disord 2013 Feb;19(2):238e41.

[34] van der Marck MA, Dicke HC, Uc EY, Kentin ZH, Borm GF, Bloem BR, et al. Body mass index in Parkinson's disease: a meta-analysis. Park Disord 2012 Mar;18(3):263e7.

[35] Aiello M, Eleopra R, Rumiati RI. Body weight and food intake in Parkinson's disease. A review of the association to non-motor symptoms. Appetite $2015 \mathrm{Jan} ; 84: 204 \mathrm{e} 11$. 
[36] Montaurier C, Morio B, Bannier S, Derost P, Arnaud P, Brandolini-Bunlon M, et al. Mechanisms of body weight gain in patients with Parkinson's disease after subthalamic stimulation. Brain 2007 Jul;130(Pt 7):1808e18.

[37] Cassani E, Barichella M, Cancello R, Cavanna F, lorio L, Cereda E, et al. Increased urinary indoxyl sulfate (indican): new insights into gut dysbiosis in Parkinson's disease. Park Relat Disord 2015 Apr;21(4):389e93.

[38] Scheperjans F, Aho V, Pereira PA, Koskinen K, Paulin L, Pekkonen E, et al. Gut microbiota are related to Parkinson's disease and clinical phenotype. Mov Disord 2015 Mar;30(3):350e8.

[39] Sharma JC, Turton J. Olfaction, dyskinesia and profile of weight change in Parkinson's disease: identifying neurodegenerative phenotypes. Park Relat Disord 2012 Sep;18(8):964e70.

[40] Agim ZS, Cannon JR. Dietary factors in the etiology of Parkinson's disease. Biomed Res Int 2015;2015:672838.

[41] Berridge MJ. Vitamin D cell signalling in health and disease. Biochem Biophys Res Commun 2015 Apr 24;460(1):53e71.

[42] Fasano A, Visanji NP, Liu LW, Lang AE, Pfeiffer RF. Gastrointestinal dysfunction in Parkinson's disease. Lancet Neurol 2015 Jun;14(6):625e39.

[43] Cereda E, Cilia R, Klersy C, Siri C, Pozzi B, Reali E, et al. Dementia in Parkinson's disease: is male gender a risk factor? Park Relat Disord 2016 May;26:67e72.

[44] Fowke JH, Schlundt D, Gong Y, Jin F, Shu XO, Wen W, et al. Impact of season of food frequency questionnaire administration on dietary reporting. Ann Epidemiol 2004 Nov;14(10):778e85.

[45] Barichella M, Pinelli G, lorio L, Cassani E, Valentino A, Pusani C, et al. Sarcopenia and Dynapenia in patients with Parkinsonism. J Am Med Dir Assoc 2016 Jul;17(7):640e6.

[46] Cereda E, Cassani E, Barichella M, Spadafranca A, Caccialanza R, Bertoli S, et al. Low cardiometabolic risk in Parkinson's disease is independent of nutritional status, body composition and fat distribution. Clin Nutr 2012 Oct;31(5): 699e704. 
Fig. 1. Distribution (McNemar's test, $P<0.001$ ) of PD patients and controls among weight status categories (UW, under-weight; NW, normal weight; OW, over-weight; OB, obesity).

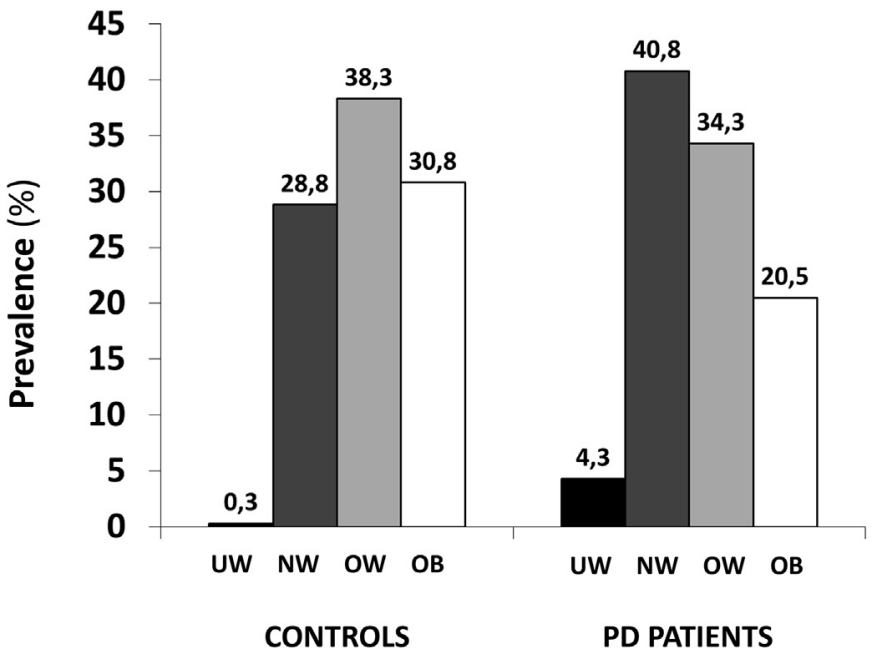


Fig. 2. Energy balance (calculated as the difference between estimated total daily energy intake and requirements) in healthy controls and Parkinson's disease (PD) patients (overall and by disease duration).

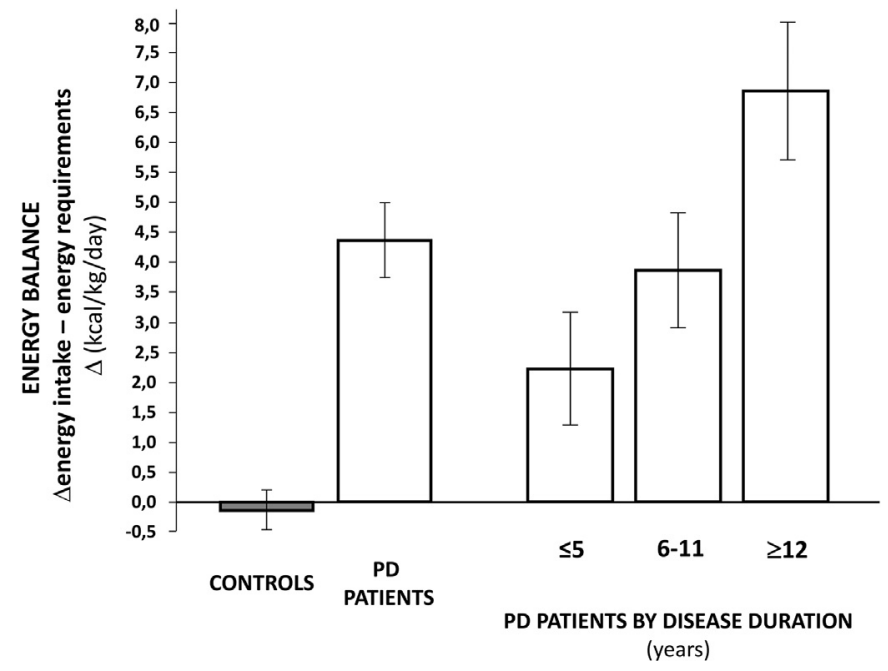




\section{Table 1}

Features (demographic, clinical and nutritional) of the study population.

\begin{tabular}{|c|c|c|c|}
\hline Variable & Controls $\left(N^{1} 1 / 4600\right)$ & PD patients $(N 1 / 4600)$ & $P$-value ${ }^{a}$ \\
\hline Male gender, $N(\%)$ & $323(53.8)$ & $323(53.8)$ & e \\
\hline Age, years [Mean (SD)] & $69.3(8.8)$ & $68.6(9.4)$ & 0.164 \\
\hline Age at onset of PD, years [Mean (SD)] & e & $59.4(11.2)$ & e \\
\hline Disease duration, years [Mean (SD)] & e & $9.2(7.0)$ & e \\
\hline Education, years [Mean (SD)] & $10.1(4.1)$ & $10.5(4.2)$ & 0.099 \\
\hline Body weight, kg [Mean (SD)] & $78.0(17.2)$ & $71.8(16.2)$ & $<0.001$ \\
\hline Body mass index, $\mathrm{kg} / \mathrm{m}^{2}$ [Mean (SD)] & $28.5(6.4)$ & $26.2(4.9)$ & $<0.001$ \\
\hline Waist circumference, cm [Mean (SD)] & $97.8(17.1)$ & $96.6(14.5)$ & 0.213 \\
\hline Levodopa dose, ${ }^{b} \mathrm{mg} /$ day [Mean (SD)] & - & $522(281)$ & - \\
\hline $\mathrm{mg} / \mathrm{kg} /$ day $[$ Mean (SD)] & - & $7.6(4.6)$ & - \\
\hline \multicolumn{4}{|l|}{ UPDRS score, Mean (SD) } \\
\hline Total & - & $42.5(17.9)$ & - \\
\hline Part I & - & $2.2(2.1)$ & \\
\hline Part II & - & $14.2(8.5)$ & \\
\hline Part III & - & $23.1(13.0)$ & \\
\hline Part IV & - & $3.0(2.9)$ & \\
\hline \multicolumn{4}{|l|}{ Motor complication score ${ }^{\mathrm{b}}$} \\
\hline Dyskinesias, ${ }^{c}$ Mean $[\mathrm{SD}]$ & - & $1.2(1.8)$ & - \\
\hline OFF state, ${ }^{\mathrm{d}}$ Mean $[\mathrm{SD}]$ & - & $1.2(1.4)$ & - \\
\hline HoehneYahr stage, Mean (SD) & - & $2.4(0.9)$ & - \\
\hline Resting energy expenditure, kcal/day [Mean (SD)] & $1488(254)$ & $1384(258)$ & $<0.001$ \\
\hline Physical activity level [Mean (SD)] & $1.41(0.12)$ & $1.40(0.13)$ & 0.167 \\
\hline TDEE, kcal/day [Mean (SD)] & $2098(395)$ & $1938(403)$ & $<0.001$ \\
\hline $\mathrm{kcal} / \mathrm{kg} /$ day [Mean (SD)] & $26.9(2.6)$ & $27.0(2.7)$ & 0.514 \\
\hline Calorie intake, kcal/day [Mean (SD)] & $2084(544)$ & $2246(557)$ & $<0.001$ \\
\hline $\mathrm{kcal} / \mathrm{kg} / \mathrm{day}$ [Mean (SD)] & $26.7(8.7)$ & $31.3(10.8)$ & $<0.001$ \\
\hline Protein intake, g/day [Mean (SD)] & $80.3(19.3)$ & $83.0(18.1)$ & 0.018 \\
\hline g/kg/day [Mean (SD)] & $1.0(0.3)$ & $1.2(0.4)$ & $<0.001$ \\
\hline Carbohydrates intake, g/day [Mean (SD)] & $265.1(78.8)$ & $293.4(85.6)$ & $<0.001$ \\
\hline Sugars intake, g/day [Mean (SD)] & $99.7(35.7)$ & $114.1(41.6)$ & $<0.001$ \\
\hline Lipids intake, g/day [Mean (SD)] & $78.1(25.8)$ & $84.2(24.7)$ & $<0.001$ \\
\hline Saturated fatty acids, g/day [Mean (SD)] & $24.6(9.3)$ & $26.8(9.2)$ & $<0.001$ \\
\hline Poly-unsaturated fatty acids, g/day [Mean (SD)] & $10.5(3.9)$ & $11.3(4.1)$ & 0.001 \\
\hline Water intake, mL/day [Mean (SD)] & $1344(474)$ & $1092(443)$ & $<0.001$ \\
\hline Fibers intake, g/day [Mean (SD)] & $30.3(8.5)$ & $32.0(8.4)$ & 0.001 \\
\hline Calcium intake, mg/day [Mean (SD)] & 1015 (299) & $1026(290)$ & 0.556 \\
\hline Iron intake, mg/day [Mean (SD)] & $13.4(3.4)$ & $13.9(3.3)$ & 0.009 \\
\hline Zinc intake, mg/day [Mean (SD)] & $11.4(2.7)$ & $11.8(2.6)$ & 0.007 \\
\hline Vitamin A intake, mg/day [Mean (SD)] & $1462(542)$ & $1561(483)$ & 0.002 \\
\hline Vitamin D intake, mg/day [Mean (SD)] & $2.6(1.3)$ & $2.6(1.1)$ & 0.813 \\
\hline
\end{tabular}


Vitamin $\mathrm{E}$ intake, mg/day [Mean (SD)

Vitamin B12 intake, mg/day [Mean (SD)]

Vitamin C intake, $\mathrm{mg} /$ day [Mean (SD)

$15.8(4.6)$

$4.5(1.8)$

$16.0(4.0)$

Folate intake, $\mathrm{mg} /$ day [Mean (SD)]

$421(127)$

$4.6(1.6)$

$10.3(13.5)$

$222(85)$

$451(124)$
$8.0(11.7)$

Alcohol intake, g/day [Mean (SD)]

Abbreviations: PD, Parkinson's disease; SD, standard deviation; TDEE, total daily energy expenditure; UPDRS, unified Parkinson's disease rating scale; RDA, recommendeddietary allowances.

\section{a According to between-group comparison by paired Student's $t$-test.}

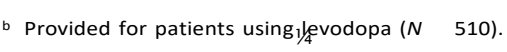

c According to UPDRS-Part IV (sum of items 32-to-35).

d According to UPDRS-Part IV (sum of items 36-to-39). 


\section{Table 2}

Characteristics of Parkinson's disease patients by disease duration (tertiles).

\begin{tabular}{|c|c|c|c|c|}
\hline \multirow[t]{2}{*}{ Variable } & \multicolumn{3}{|l|}{ Disease duration } & \multirow[t]{2}{*}{$P$-value } \\
\hline & $\leq 5$ years $(N 1 / 4202)$ & 6e11 years $\left(N \frac{1}{1} / 218\right)$ & $\geq 12$ years $\left(N \frac{1}{1} / 4180\right)$ & \\
\hline Male gender, $N(\%)$ & $104(51.5)$ & $112(51.4)$ & $103(57.2)$ & $0.323^{\mathrm{a}}$ \\
\hline Age, years & $67.6(9.8)$ & $69.1(9.2)$ & $69.0(9.2)$ & $0.189^{\mathrm{a}}$ \\
\hline Disease duration, years & $3.0(1.6)$ & $8.1(1.7)$ & $17.5(6.6)$ & $<0.001^{\mathrm{a}}$ \\
\hline HoehneYahr stage, Mean (SD) & $2.2(0.9)^{*}$ & $2.4(0.9)^{*}$ & $2.7(0.8)^{*}$ & $<0.001^{\mathrm{b}}$ \\
\hline \multicolumn{5}{|l|}{ Motor complication score $^{d}$} \\
\hline Dyskinesias, ${ }^{e}$ Mean $[\mathrm{SD}]$ & $0.5(1.4)^{*}$ & $1.1(1.7)^{*}$ & $1.9(1.9)^{*}$ & $<0.001^{\mathrm{b}}$ \\
\hline OFF state, ${ }^{f}$ Mean $[\mathrm{SD}]$ & $0.5(1.0)^{*}$ & $1.0(1.3)^{*}$ & $2.1(1.4)^{*}$ & $<0.001^{\mathrm{b}}$ \\
\hline \multirow{2}{*}{$\begin{array}{l}\text { Levodopa dose d, mg/day [Mean (SD)] } \\
\mathrm{mg} / \mathrm{kg} / \text { day [Mean (SD)] }\end{array}$} & $380(156)$ & $540(304)$ & $626(291)$ & $<0.001^{\mathrm{b}}$ \\
\hline & $5.3(2.2)$ & $7.9(5.0)$ & $9.4(4.9)$ & $<0.001^{\mathrm{b}}$ \\
\hline Body weight, kg [Mean (SD)] & $73.1(15.5)$ & $72.2(17.0)$ & $70.0(16.0)$ & $0.046^{\mathrm{b}}$ \\
\hline Body mass index, $\mathrm{kg} / \mathrm{m}^{2}$ [Mean (SD)] & $26.6(4.6)$ & $26.5(4.8)$ & $25.5(4.7)^{*}$ & $0.040^{\mathrm{b}}$ \\
\hline Resting energy expenditure, kcal/day [Mean (SD)] & $1412(256)$ & $1387(269)$ & $1349(246)$ & $0.044^{\mathrm{b}}$ \\
\hline Physical activity level [Mean (SD)] & $1.42(0.13)$ & $1.40(0.12)$ & $1.39(0.11)$ & $0.048^{\mathrm{b}}$ \\
\hline \multirow{2}{*}{$\begin{array}{l}\text { Total daily energy expenditure, kcal/day [Mean (SD)] } \\
\mathrm{kcal} / \mathrm{kg} / \text { day [Mean (SD)] }\end{array}$} & $2005(398)$ & $1942(421)$ & $1875(384)$ & $0.040^{\mathrm{b}}$ \\
\hline & $27.4(2.5)$ & $26.9(2.6)$ & $26.8(2.5)$ & $0.050^{\mathrm{b}}$ \\
\hline \multirow{2}{*}{$\begin{array}{l}\text { Calorie intake, kcal/day [Mean (SD)] } \\
\mathrm{kcal} / \mathrm{kg} / \text { day [Mean (SD)] }\end{array}$} & $2166(554)$ & $2224(542)$ & $2362(564)^{*}$ & $0.002^{\mathrm{b}}$ \\
\hline & $29.6(9.9)$ & $30.8(10.7)$ & $33.7(11.4)^{*}$ & $<0.001^{\text {b }}$ \\
\hline \multirow{2}{*}{$\begin{array}{l}\text { Protein intake, g/day [Mean (SD)] } \\
\text { g/kg/day [Mean (SD)] }\end{array}$} & $80.3(19.3)$ & $80.3(19.3)$ & $83.0(18.1)^{*}$ & $0.006^{\mathrm{b}}$ \\
\hline & $1.1(0.3)$ & $1.1(0.4)$ & $1.2(0.4)^{*}$ & $<0.001^{b}$ \\
\hline Constipation, $N(\%)$ & $72(35.6)$ & 111 (50.9)y & $98(54.4) y$ & $<0.001^{c}$ \\
\hline
\end{tabular}

a According to Fisher's exact test (categorical variables) or one-way analysis of variance (continuous variables).

b According to sex and age-adjusted analysis of covariance (* significantly different from the other groups by Bonferroni corrected pairwise comparison).

${ }^{\mathrm{C}}$ For trend according to sex and age-adjusted logistic regression (y significantly different from the reference category [disease duration $\leq 5$ years]).

${ }^{d}$ Provided for patients using levodopa ( $N$ 1/4 510 e $\leq 5$ years, $N$ 11/4 150; 6e11 years, $N$ 1/4 191; $\geq 12$ years, $N$ 11/4 169).

According to UPDRS-Part IV (sum of items 32-to-35).

f According to UPDRS-Part IV (sum of items 36-to-39). 


\section{Table 3}

Linear regression of variables associated with daily levodopa dose $(\mathrm{mg} / \mathrm{kg} / \mathrm{day}$; patients receiving levodopa therapy [ $\mathrm{N}=510])$.

Univariable linear regression models

b-coefficient (SE) $(\mathrm{mg} / \mathrm{kg} / \mathrm{day})$

\section{Age at onset (years)}

Male gender

Disease duration (years)

HoehneYahr stage (1-class increase)

Dopamine-agonist use (yes)

Constipation (yes)

Excess in protein intake $\mathrm{a}(\mathrm{g} / \mathrm{day})$

Protein redistribution diet (yes)

$0.083(0.022)$

$0.180(0.028)$

$1.065(0.262)$

$1.023(0.465)$

$1.054(0.411)$

$0.084(0.008)$

$-1.059(0.423)$

Abbreviations: SE, standard error.

Amount exceeding the physiological requirements $(0.8 \mathrm{~g} / \mathrm{kg} / \mathrm{day})$

b The "Model 1" did not include disease duration and severity.

"The "Model 2" included all the variables listed.
Multivariate analysis (Model 1$)^{b}$

Multivariate analysis (Model 2)

$P$-value $\quad$-coefficient (SE) $(\mathrm{mg} / \mathrm{kg} /$ day)

$0.109(0.247)$

$\begin{array}{ccc}0.001 & -0.109(0.247) \\ 0.363 & 0.321 & (0.468)\end{array}$

$<0.001$ e

$<0.001$

$0.058(0.011)$

$0.006-0.998(0.446)$

\begin{tabular}{|c|c|c|}
\hline$\overline{P \text {-value }}$ & $\overline{b \text {-coefficient (SE) }(\mathrm{mg} / \mathrm{kg} / \text { day) }}$ & $P$-value \\
\hline$<0.001$ & $0.061(0.025)$ & 0.014 \\
\hline 0.494 & $0.01(0.444)$ & 0.984 \\
\hline e & $0.198(0.036)$ & $<0.001$ \\
\hline e & $0.719(0.282)$ & 0.011 \\
\hline 0.110 & $0.678(0.462)$ & 0.143 \\
\hline 0.035 & $0.741(0.365)$ & 0.041 \\
\hline$<0.001$ & $0.071(0.010)$ & $<0.001$ \\
\hline 0.012 & $-0.847(0.419$ & \\
\hline
\end{tabular}

